\title{
Change in mass balance of polar ice sheets and sea level from high-resolution GCM simulations of greenhouse warming
}

\author{
Martin Wild, Atsumu Ohmura \\ Department of Geography, Swiss Federal Institute of Technology, CH-8057 Zürich, Switzerland
}

\begin{abstract}
For projecting future sea level, the mass-balance changes on Greenland and Antarctica are considered to be crucial. Promising tools for such estimates are general circulation models (GCM). Until recently, a major impediment was their coarse grid resolution $\left(3^{\circ}-6^{\circ}\right)$ causing substantial uncertainties in the mass-balance calculations of the poorly resolved ice sheets. The present study is based on a new climate-change experiment of the highest resolution currently feasible $\left(1.1^{\circ}\right)$ performed with the ECHAM4 T106 GCM, thereby increasing confidence in the projected mass-balance and sea-level changes. This new experiment, with doubled $\mathrm{CO}_{2}$ concentration, suggests that the mass gain in Antarctica due to increased accumulation exceeds the melt-induced mass loss in Greenland by a factor of three. The resulting mass-balance change on both ice sheets is equivalent to a net sea-level decrease of $0.6 \mathrm{~mm} \mathrm{a}^{-1}$ under doubled $\mathrm{CO}_{2}$ conditions. This may compensate for a significant portion of the melt-induced sea-level rise from the smaller glaciers and ice caps, thus leaving thermal expansion as the dominant factor for sea-level rise over the next decades. This compensating effect, however, no longer applies should atmospheric $\mathrm{CO}_{2}$ concentration reach levels well above "doubled the present value". On the contrary, under these conditions, the greenhouse warming would become large enough to induce substantial melting also on the Antarctic ice sheet, thereby significantly accelerating global sea-level rise.
\end{abstract}

\section{INTRODUCTION}

The prospect of significant changes in global sea level due to greenhouse warming has raised much scientific and public concern. A key factor controlling global sea level is the mass balance of Greenland and Antarctica, which include 97\% of the world's glacierized surface. Changes in the mass balance of these ice sheets have the potential to significantly affect global sea level.

A realistic simulation of the mass balance of polar ice sheets requires model resolutions which exceed those typically used in global-climate simulations up to now (T42-T21 spectral resolution, corresponding to a $3^{\circ}-6^{\circ}$ grid) (e.g. Thompson and Pollard, 1997). With recent developments in computing it has become possible to perform multi-annual simulations at spectral resolutions up to T106 (corresponding to a horizontal grid resolution of $1.1^{\circ}$ or approximately $100 \mathrm{~km})$. It has been shown that through an increase in horizontal resolution of this magnitude the simulated mass balance on the polar ice sheets can be significantly improved, for the following reasons:

(i) The precipitation distribution over the polar ice sheets is strongly dependent on orographic forcing. The representation of orography improves considerably with higher resolution (cf. Fig. 1). Ohmura and others (1996b) found a substantial improvement in precipitation over the polar ice sheets in the T106 simulations with the ECHAM3 GCM of the Max Planck Institute for Meteorology, Hamburg, compared to lower-resolution integrations with the same model. Genthon and others (1994) documented the improved simulation of accumulation over Greenland in a T79 version of the ARPÈGE (Action Recherche Petite Échelle Grande Échelle) model compared to lower model resolutions.

(ii) The ablation areas on the steep margins of the ice sheets are much better resolved in higher-resolution models, allowing for a more appropriate calculation of ablation. The accurate calculation of ablation in the high-resolution ECHAM3 T106 model was documented in Ohmura and others (1996a, b).

The first climate-change experiment at T106 resolution, performed with the ECHAM3 GCM, was evaluated in Ohmura and others $(1996 \mathrm{a}, \mathrm{b})$ with respect to the massbalance changes of the polar ice sheets. The present study focuses on the mass-balance changes of the polar ice sheets as calculated in more sophisticated T106 time-slice experiments with the most recent model version, ECHAM4, and on the comparison of these results with the ones obtained previously in the ECHAM3 T106 experiments (Ohmura and others, 1996a, b).

\section{MODELS AND EXPERIMENTAL SETUP}

As noted above, the model used in this study is the ECHAM4 GCM (Roeckner and others, 1996), which is the latest version of the ECHAM model series developed at the Max Planck Institute for Meteorology, Hamburg (MPI). These GCMs have evolved from the spectral numerical weather-fore- 

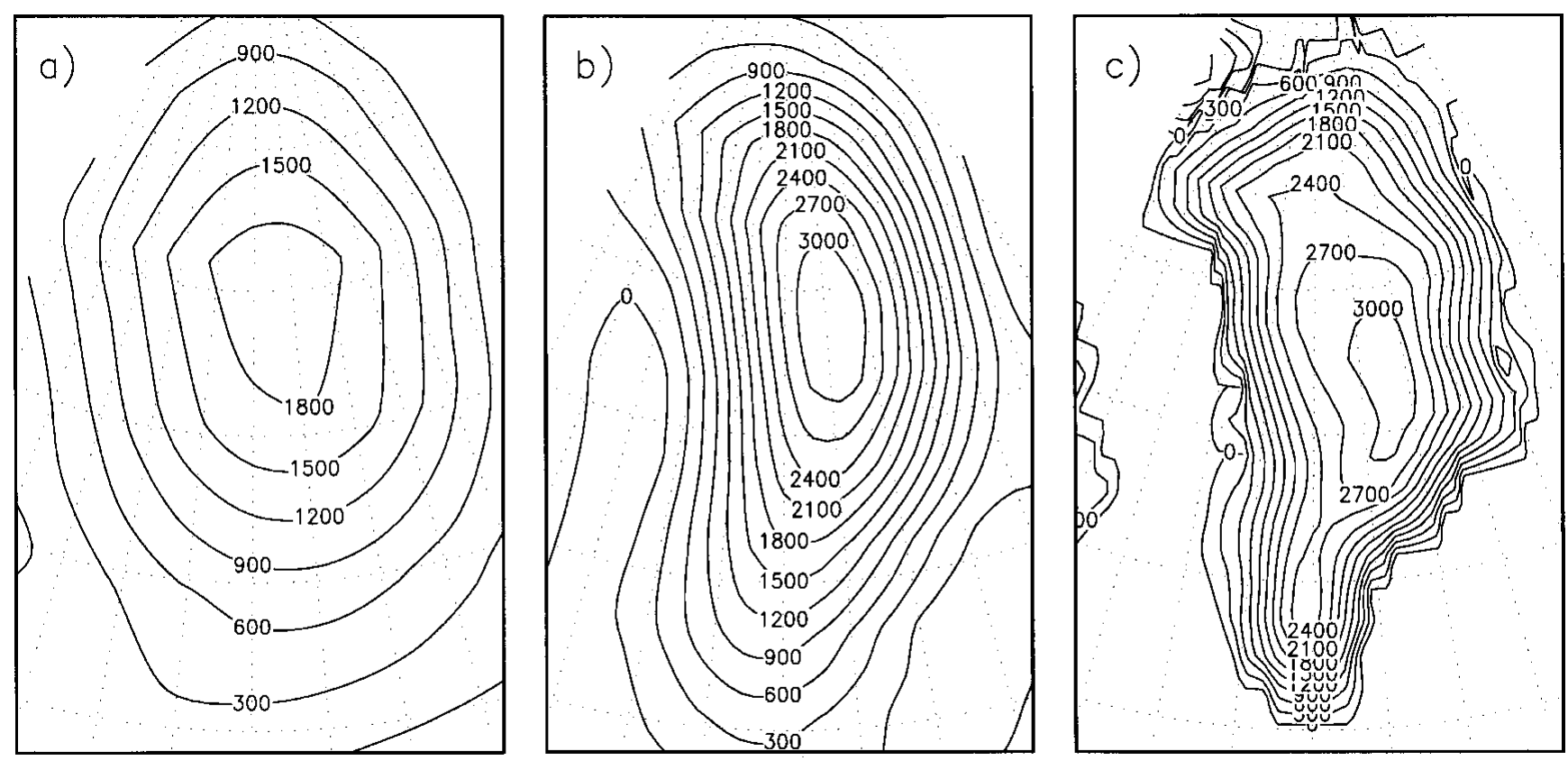

(m)

Fig. 1. Representation of the Greenland orography $(m)$ in models with various horizontal resolutions: (a) T21 (5.6 $\left.6^{\circ}\right)$; (b) T42 $\left(2.8^{\circ}\right)$; and (c) $T 106\left(1.1^{\circ}\right)$.

casting model of the European Centre for Medium-range Weather Forecasts (ECMWF) and have been extensively modified in Hamburg for climate applications. Compared to the precursor model version ECHAM3 (Roeckner and others, 1992), ECHAM4 incorporates revisions in a number of key climatic processes, as described in Roeckner and others (1996). A major change consists in the introduction of a new radiation scheme based on Morcrette (1991), with modifications in the water-vapor continuum (Giorgetta and Wild, 1995). For advection of water vapour and cloud water, the spectral method has been replaced by a semi-Lagrangian transport method (Williamson and Rasch, 1989). The closure for penetrative convection in the Tiedtke (1989) mass-flux scheme has been revised. In the parameterization scheme of the planetary boundary layer, the first-order turbulence closure is replaced by a turbulent kinetic-energy closure (Brinkop and Roeckner, 1995). A new global dataset of landsurface parameters is used in ECHAM4 (Claussen and others, 1994), constructed from major ecosystem complexes. Several studies have documented improvements in various
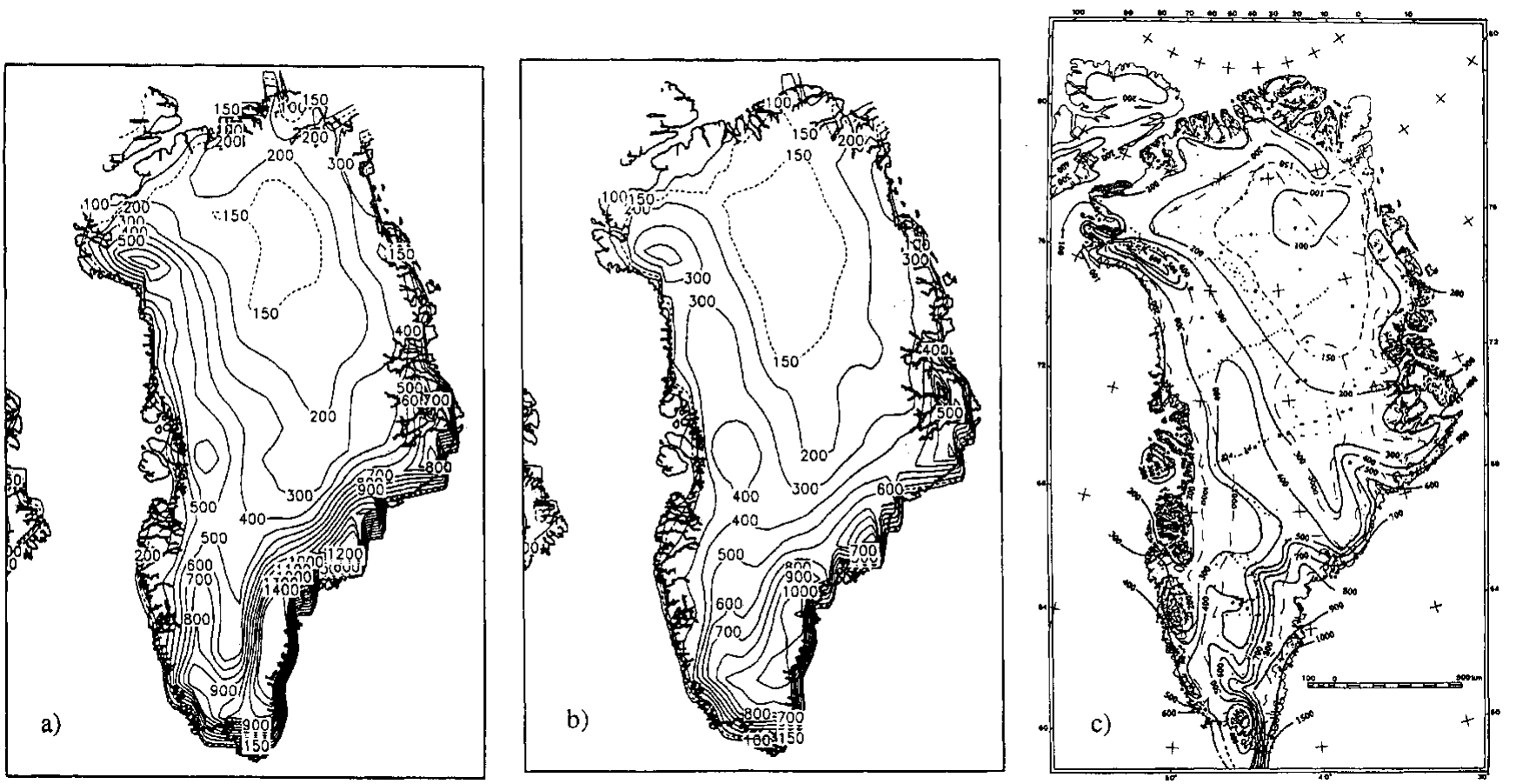

Fig. 2. Annual mean accumulation over Greenland $\left(\mathrm{mm} \mathrm{a}^{-1}\right)$ under present climatic conditions. Model calculations with (a) ECHAM3 T106 and (b) ECHAM4 T106 compared to (c) the new climatology of Ohmura and others (1999). 
Table 1. Present-day annual accumulation and ablation integrated over the Greenland and Antarctic ice sheets, calculated with ECHAM3 T106 and ECHAM4 T106 and observed

\begin{tabular}{lccc}
\hline & $\begin{array}{c}\text { ECHAM3 } \\
\mathrm{mm} \mathrm{a}^{-1}\end{array}$ & $\begin{array}{c}\text { ECHAM4 } \\
\mathrm{mm} \mathrm{a}^{-1}\end{array}$ & $\begin{array}{c}\text { Observed } \\
\mathrm{mm} \mathrm{a}^{-1}\end{array}$ \\
\hline $\begin{array}{l}\text { Accumulation } \\
\text { Greenland }\end{array}$ & 426 & 331 & 297 \\
Antarctica & 197 & 166 & $147-184$ \\
Ablation & 146 & 204 & 200 \\
Greenland & - & - & - \\
Antarctica & & & \\
\hline
\end{tabular}

Notes: Observed accumulation over Greenland from Ohmura and others (1999), observed ablation from Ohmura and others (1996a). Observed accumulation over Antarctica from various sources as given in Ohmura and others (1996a).

aspects of the simulated climate in ECHAM4 (e.g. Roeckner and others, 1996; Wild and others, 1996, 1998).

In the framework of the European Union Project SIDDACLICH (SImulation, Detection and Diagnosis of Anthropogenic CLImate CHange), climate-change scenarios of unprecedented high resolution have been performed jointly by the Swiss Federal Institute of Technology, Zürich, and the MPI. The aim was thereby to obtain climate-change scenarios at the highest resolution currently used in climate modeling, namely at $\mathrm{T} 106\left(1.1^{\circ}\right)$. Since it is not feasible to run such a highresolution GCM over several decades with today's supercomputing resources, as required in transient climate-change experiments, "time-slice" experiments were performed (Cubasch and others, 1995; Wild and others, 1997). In this manner the high-resolution atmospheric model can be run over the time window where the $\mathrm{CO}_{2}$ concentration is expected to double, using prescribed boundary conditions of sea-surface temperature (SST) and sea-ice distribution predicted by a lower-resolution, transient, coupled atmosphereocean scenario run. T106 $\left(1.1^{\circ}\right)$ experiments with ECHAM4 have been carried out for both present-day and $2 \times \mathrm{CO}_{2}$ conditions using the associated SST and sea-ice distributions from a new transient scenario run with the ECHAM4 at T42 $\left(2.8^{\circ}\right)$ resolution coupled to the OPYG ocean model (Roeckner and others, 1999). This scenario run takes into account a gradual increase in $\mathrm{CO}_{2}$ and other greenhouse gases according to the Intergovernmental Panel on Climate Change Scenario IS92a (Leggett and others, 1992), with an expected $\mathrm{CO}_{2}$ doubling after 70 years. Prior to that, an analogous experiment was performed with the precursor model version ECHAM3 T106, using the boundary conditions from an older scenario run with model version ECHAM1 at coarser resolution (T21, 5.6 ${ }^{\circ}$ ) and the LSG ocean model (Cubasch and others, 1992). The mass-balance changes over the polar ice sheets in this experiment were evaluated in Ohmura and others (1996a, b). While the ECHAM3 T106 model was integrated for 5 years for both present and $2 \times \mathrm{CO}_{2}$ conditions, the ECHAM4 T106 experiments were each extended to 10 years, thereby ensuring statistically more significant results. Furthermore, the ECHAM4 model has been improved in major aspects compared to its precursor version ECHAM3 (e.g. Roeckner and others, 1996; Wild and others, 1996, 1998). Since the new ECHAM4 T106 time-slice experiments were integrated over a longer period with an improved model, and with SST boundary conditions from a newer and more sophisticated transient experiment, these are considered to be the most adequate experiments for the objectives of the present study. A re-evaluation of the massbalance changes over the polar ice sheets under greenhouse warming has therefore been considered indispensable.

\section{ACGUMULATION}

For the assessment of the model-calculated accumulation (solid precipitation minus evaporation) over Greenland under present-day conditions, a new observational reference is used (Ohmura and others, 1999) (Fig. 2). This reference is based on the re-evaluation of the climatology of Ohmura and Reeh (1991), using additional information from about 50 shallow to medium-deep ice cores and wind-corrected precipitation measurements observed at coastal meteorological stations. Furthermore, for each station, the total precipitation is divided into liquid and solid phase in the transitional seasons based on a relationship between the ratio of solid precipitation to total precipitation and mean air temperature, developed recently at the authors' institute. A comparison of this new climatology with the accumulation as calculated in the highresolution ECHAM3 and ECHAM4 T106 experiments for present-day conditions qualitatively reveal a very good agreement of both models in the regional accumulation pattern (Fig. 2). Quantitatively, however, ECHAM3 generally tends to overestimate the accumulation. This overestimation is less pronounced in the ECHAM4 model. This is also apparent in the annual mean accumulation over Greenland which is, at $331 \mathrm{mma}^{-1}$, closer to the new observational estimate of $297 \mathrm{~mm} \mathrm{a}^{-1}$ given in Ohmura and others (1999) (cf. Table 1).
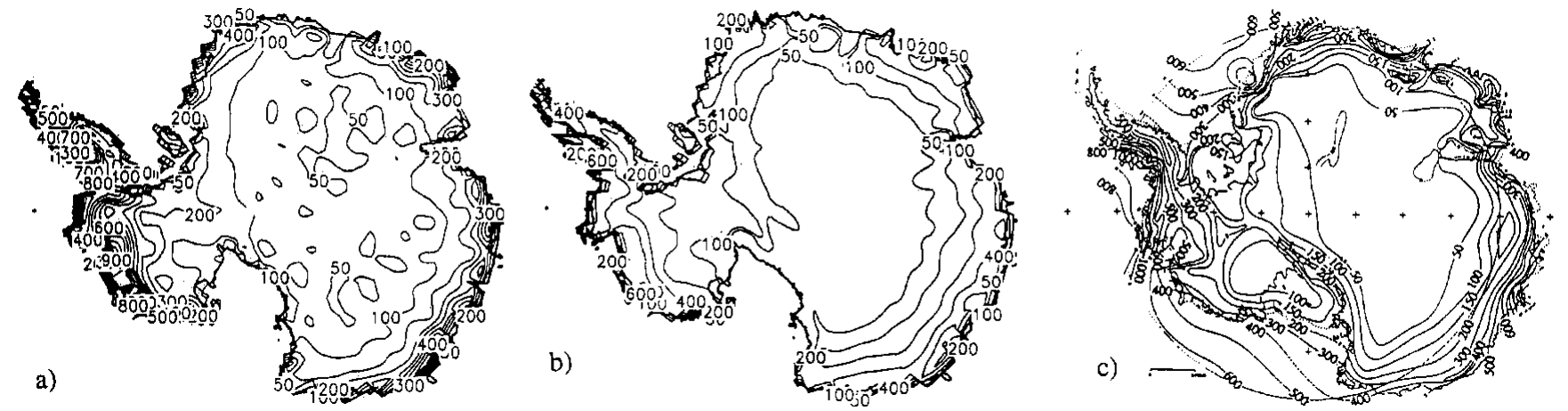

Fig. 3. Annual mean accumulation over Antarctica $\left(\mathrm{mm} \mathrm{a}^{-1}\right)$ under present climatic conditions. (a) Model calculations with ECHAM3 T106 and (b) ECHAM4 T106 compared to (c) the climatology of Giovinetto and others (1990). 


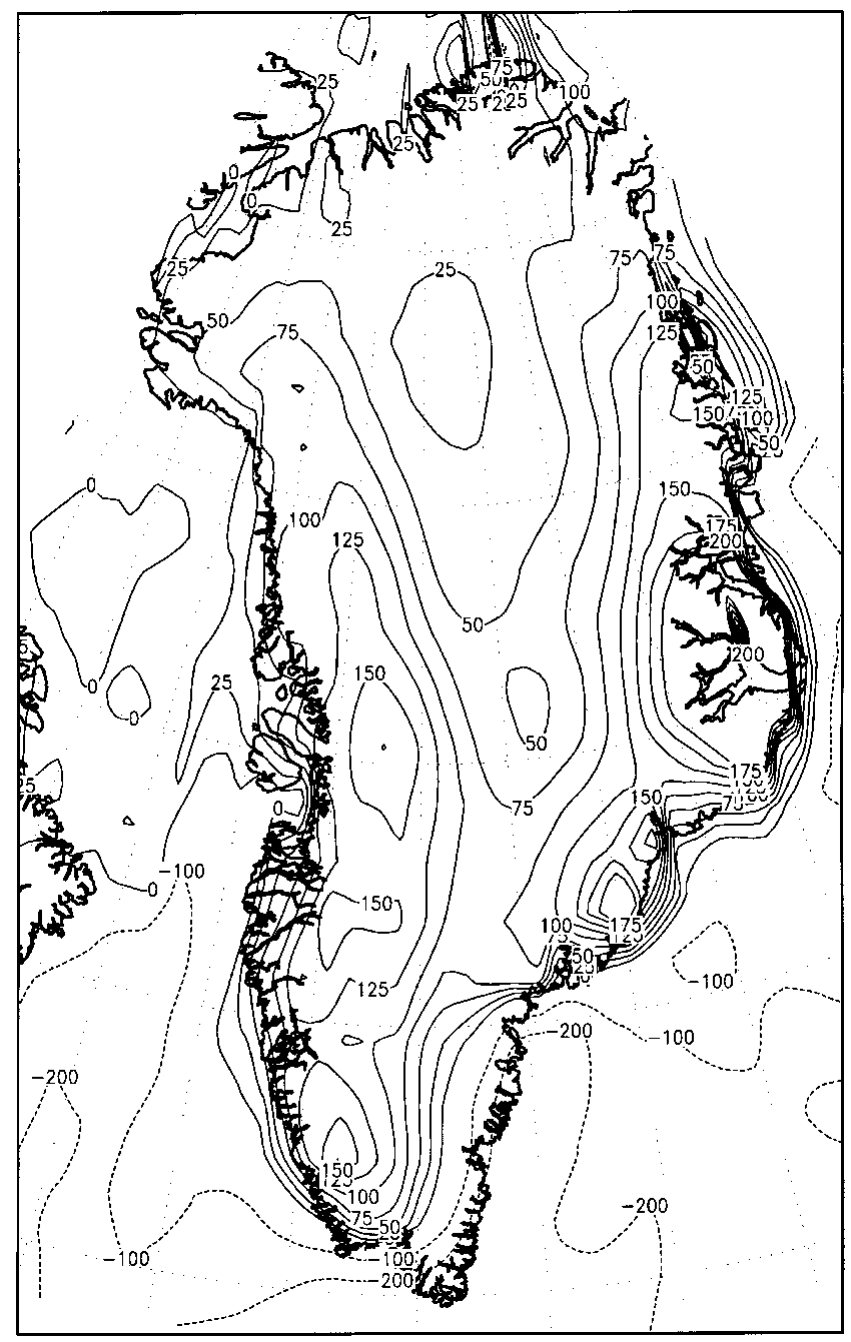

Fig. 4. Change in annual accumulation over Greenland $\left(\mathrm{mm} \mathrm{a}^{-1}\right)$ as projected by ECHAM4 $\mathrm{T106}$ with doubled $\mathrm{CO}_{2}$ concentration; calculated as difference between the $2 \times \mathrm{CO}_{2}$ time-slice scenario and the present-climate experiment.

Table 2. Change in mass balance of the polar ice sheets and contribution to sea-level changes as projected in high resolution ( T106) $2 \times \mathrm{CO}_{2}$ scenarios with the ECHAM3 and ECHAM4 models

ECHAMЗ ECHAM4

$\mathrm{mma}^{-1} \quad \mathrm{mma}^{-1}$

\section{Greenland}

Accumulation change

Ablation change

Mass-balance change

$-21$

$-208$

$-229$

$+92$

$\Rightarrow$ Greenland contribution to sea-level change

$+1.13$

$-155$

Antarctica

Accumulation change

Ablation change

Mass-balance change

$\Rightarrow$ Antarctic contribution to sea-level change

$\Rightarrow$ Net contribution of polar ice sheets to

sea-level change

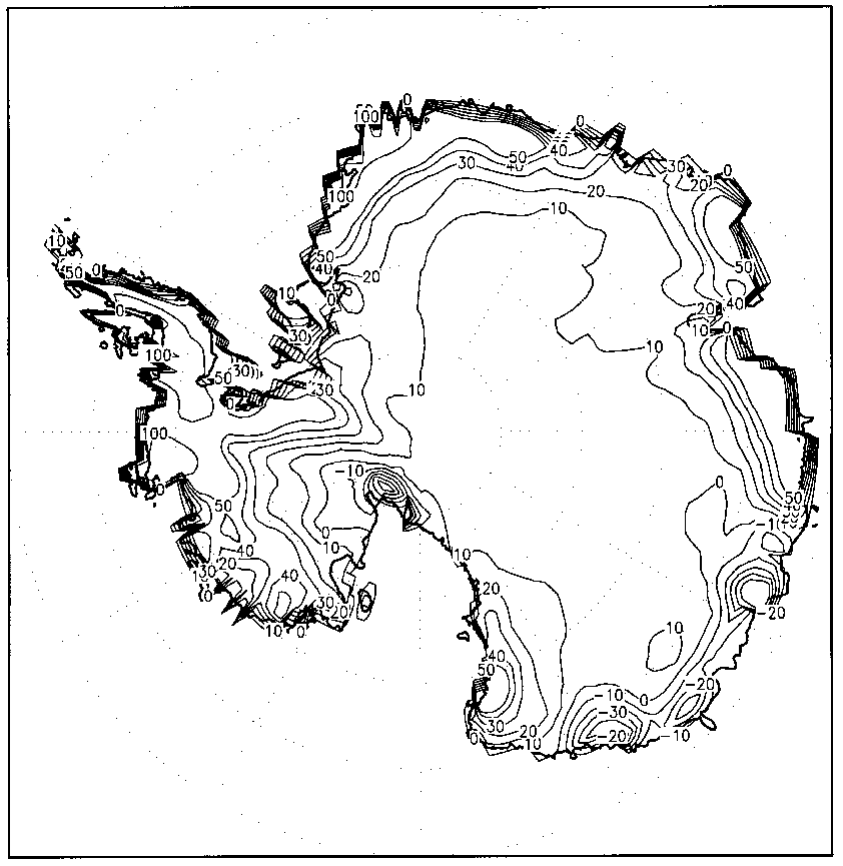

Fig. 5. Change in annual accumulation over Antarctica $\left(m m a^{-1}\right)$ as projected by ECHAM4 $\mathrm{T106}$ with doubled $\mathrm{CO}_{2}$ concentration; calculated as difference between the $2 \times \mathrm{CO}_{2}$ time-slice scenario and the present-climate experiment.

ECHAM3 and other previous experiments used to estimate mass-balance changes, conversely, overestimated accumulation over Greenland under present climate far more seriously, exceeding the newly evaluated value of $297 \mathrm{~mm} \mathrm{a}^{-1}$ by $40 \%$ and more (cf. Table 1). Over Antarctica, the ECHAM4 T106-calculated accumulation shows a very realistic regional pattern when compared to the climatology of Giovinetto and others (1990) (Fig. 3). The annual mean accumulation over Antarctica amounts to $166 \mathrm{~mm} \mathrm{a}^{-1}$ (Table 1) in ECHAM4 T106, which is well within the range of observational estimates from $147-184 \mathrm{~mm} \mathrm{a}^{-1}$ listed in Ohmura and others (1996a). The ECHAM3 T106 accumulation, on the other hand was, at $197 \mathrm{~mm} \mathrm{a}^{-1}$, somewhat outside this range (Table 1). The accumulation in the interior of the Antarctic ice sheet, in particular, is overestimated in ECHAM3, a feature no longer present in ECHAM4.

The above findings underline the improved representation of accumulation over both Greenland and Antarctica in the new high-resolution experiments and enhances confidence in the projected changes in future climates.

In the ECHAM4 T106 $2 \times \mathrm{CO}_{2}$ experiment, the accumulation over Greenland increases on average by $92 \mathrm{~mm} \mathrm{a}^{-1}$ (Fig. 4, Table 2). This marks a substantial revision of the estimates obtained in the previous ECHAM3 T106 scenario, which showed a slight decrease in accumulation. Seasonally, Table 3 shows that the increase in the ECHAM4 accumulation is largest in the winter season $\left(+182 \mathrm{~mm} \mathrm{a}^{-1}\right)$, in line with the highest temperature increase during winter $\left(+4.5^{\circ}\right)$. The large accumulation increase in winter, which was not found in ECHAM3, is caused by a slight northward displacement of the Icelandic low and an associated increase in the pressure gradient along the coast of Greenland up to Baffin Bay, affecting also the west coast of Greenland to Disco island. This change in the atmospheric circulation is favourable for supplying more water vapour especially to the east coast and the southern half of the west coast. 
Table 3. Seasonal change in accumulation $(\Delta A c c)$ and temperature $(\Delta T)$ over the polar ice sheets as projected by $E C$ HAM4 T106 under doubled $\mathrm{CO}_{2}$ concentration, calculated as difference between the $2 \times \mathrm{CO}_{2}$ time-slice scenario and the present climate experiment

\begin{tabular}{lcc}
\hline & $\begin{array}{c}\Delta T \\
\end{array}$ & $\begin{array}{c}\Delta A c c \\
{ }^{\circ} \mathrm{C}\end{array}$ \\
& & \\
\hline Greenland & \\
Winter (December-January-February mean) & 4.5 & +182 \\
Spring (March-April-May mean) & 4.0 & +92 \\
Summer (June-July-August mean) & 2.3 & -24 \\
Autumn (September-October-November mean) & 2.7 & +116 \\
Antarctica & & \\
Summer (December-January-February mean) & 1.7 & +23 \\
Autumn (March-April-May mean) & 2.6 & +35 \\
Winter (June-July-August mean) & 1.6 & +21 \\
Spring (September-October-November mean) & 1.5 & +10 \\
& & \\
\hline
\end{tabular}

Over Antarctica, annual accumulation increases by $22 \mathrm{~mm} \mathrm{a}^{-1}$ (Fig. 5, Table 2) in the ECHAM4 scenario, an amount almost identical to the previous ECHAM3 experiment $\left(23 \mathrm{~mm} \mathrm{a}^{-1}\right)$. The accumulation change is thus very similar in both old and new experiments. The seasonal increase in accumulation in the ECHAM4 scenario is in line with the seasonal temperature increase as can be inferred from Table 3. In addition to the temperature increase, the increased low-pressure activities in the sub-Antarctic lowpressure zone are responsible for the increase in accumulation in the scenario experiments throughout the year, especially for the marginal zones of the ice sheets. This is found consistently in both ECHAM4 and ECHAM3 scenarios. Regional differences between the old and new scenario become visible mainly in the interior of East Antarctica with the larger accumulation increase in ECHAM4. This is related to a decrease in surface pressure over East Antarctica, which is stronger in ECHAM4 than in ECHAM3. Over Wilkes Land, on the other hand, ECHAM4 projects a significant decrease in accumulation in summer which is less pronounced in ECHAM3. In general, however, it can be noted that the response of accumulation over Antarctica to the $2 \times \mathrm{CO}_{2}$ forcing is very consistent in both old and new experiments.

\section{ABLATION}

Since ablation is not explicitly calculated in the model, a linear relationship between calculated summer temperature $T_{\text {JJA }}$ (in ${ }^{\circ} \mathrm{G}$ ) and ablation $A$ (in $\mathrm{mm} \mathrm{a}^{-1}$ ) is used, having been derived from extensive observations in Greenland (Ohmura and others, 1996a):

$$
A=514 T_{\mathrm{JJA}}+930 .
$$

Applying Equation (1) in ECHAM4 T106 to present-day conditions yields an ablation of $203 \mathrm{~mm} \mathrm{a}^{-1}$ on Greenland, in line with the observational estimate, which uses the same relationship, but applied to observed temperature data (Table 1). The increase in ablation, with the warming in the ECHAM4 $2 \times \mathrm{CO}_{2}$ experiment shown in Figure 6 , is projected at $155 \mathrm{~mm} \mathrm{a}^{-1}$. This is somewhat lower, yet of similar magnitude compared to the ablation change in the ECHAM3 scenario (cf. Table 2). The inland shift of the $-2^{\circ} \mathrm{C}$ isoline, which en-



Fig. 6. Change in summer (June-Fuly-August mean) temperature over Greenland $\left({ }^{\circ} \mathrm{C}\right)$ as projected by ECHAM4 T106 with doubled $\mathrm{CO}_{2}$ concentration, calculated as difference between the $2 \times \mathrm{CO}_{2}$ time-slice scenario and the presentclimate experiment.

closes the discharge-producing area according to Equation (1), amounts to $45 \mathrm{~km}$ in the ECHAM4 scenario on average, compared to $69 \mathrm{~km}$ in the ECHAM 3 scenario. This is equivalent to an increase in the areal extent of the discharge-producing area by $215000 \mathrm{~km}^{2}$ in ECHAM4 and $353000 \mathrm{~km}^{2}$ in ECHAM3, and in line with the somewhat lower ablation increase in ECHAM4 compared to ECHAM3 (Table 2).

The temperature over Antarctica is too low for significant melt under present climatic conditions. Even in the $2 \times \mathrm{CO}_{2}$ scenario, the temperature increase in summer (Fig. 7) is not sufficient to produce any significant melt. This can be inferred from Figure 8, where the temperature distribution over Antarctica in the ECHAM4 $2 \times \mathrm{CO}_{2}$ scenario is shown for the Southern Hemisphere summer (DecemberJanuary-February) mean. The $-2^{\circ} \mathrm{C}$ isoline, which marks the lowest summer temperature where ablation can occur (cf. Equation (1)), does not reach the Antarctic ice sheet, which is therefore also too cold for any significant ablation under $2 \times \mathrm{CO}_{2}$ conditions. This is likewise found in both EGHAM3 and ECHAM4 scenarios. It should be noted, however, that little further warming is required to raise temperatures on the margins of the Antarctic ice sheet above the $-2{ }^{\circ} \mathrm{C}$ threshold. Thus, if the increase of atmospheric $\mathrm{CO}_{2}$ concentration could not be stopped at double the present 


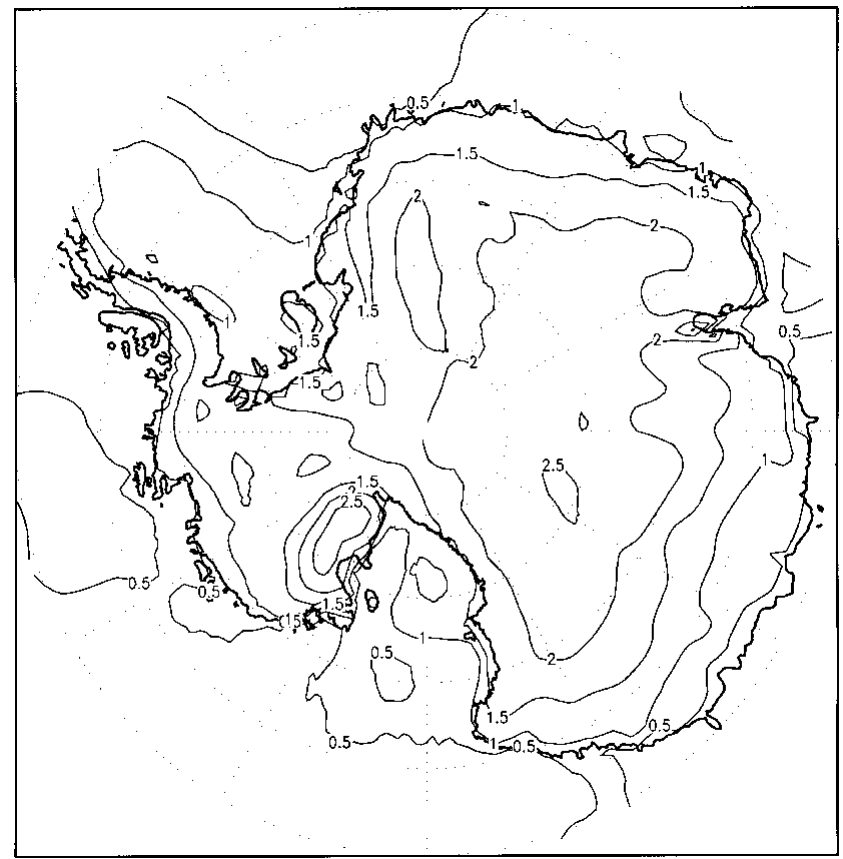

Fig. 7. Change in summer (December-January-February mean) temperature over Antarctica $\left({ }^{\circ} \mathrm{C}\right)$ as projected by $E C$ HAM4 $\mathrm{T} 106$ with doubled $\mathrm{CO}_{2}$ concentration; calculated as difference between the $2 \times \mathrm{CO}_{2}$ time-slice scenario and the present-climate experiment.

value, further greenhouse warming would initiate significant melt from the Antarctic ice sheet.

\section{NET MASS-BALANGE GHANGES AND CONSE- QUENCES FOR SEA LEVEL}

In the ECHAM4 scenario, the aforementioned changes in accumulation and ablation lead to an alteration in mass balance of $-63 \mathrm{~mm} \mathrm{a}^{-1}$ over Greenland. This corresponds to an annual total mass loss at $2 \times \mathrm{CO}_{2}$ of $110 \mathrm{~km}^{3}$, which is significantly smaller than in the former ECHAM3 scenario and mainly due to the difference in accumulation (Table 1).

Over Antarctica, the mass-balance increases by $22 \mathrm{~mm} \mathrm{a}^{-1}$ in the ECHAM4 $2 \times \mathrm{CO}_{2}$ scenario due to accumulation changes only, corresponding to a total annual mass gain of $305 \mathrm{~km}^{3}$ (Table 2). This amount is almost identical to the ECHAM3 scenario.

Overall, this indicates that in the new ECHAM4 T106 scenario, the mass gain in Antarctica dominates the mass loss in Greenland almost by a factor of three, while in the former ECHAM3 T106 scenario, the larger mass loss in Greenland nearly compensated for the mass gain in Antarctica.

In terms of sea-level change, this corresponds to a sea-level fall due to the polar ice sheets of $0.6 \mathrm{~mm} \mathrm{a}^{-1}$ in the ECHAM4 scenario, while the ECHAM3 scenario gave an estimate close to zero (sea-level rise of $0.2 \mathrm{~mm} \mathrm{a}^{-1}$ ). Assuming a linear behaviour in the mass-balance changes, the new estimate in the ECHAM4 scenario is equivalent to a sea-level fall of $21 \mathrm{~mm}$ at the time of $2 \times \mathrm{CO}_{2}$ compared to present day.

The $0.6 \mathrm{~mm} \mathrm{a}^{-1}$ decrease in sea level at the time of $2 \times \mathrm{CO}_{2}$ projected in the new ECHAM4 scenario caused by the polar ice sheets may be able to compensate for about half of the sealevel rise induced by the melting of mountain glaciers and small ice caps projected in other recent studies (Warrick and others, 1996; Gregory and Oerlemans, 1998). This would

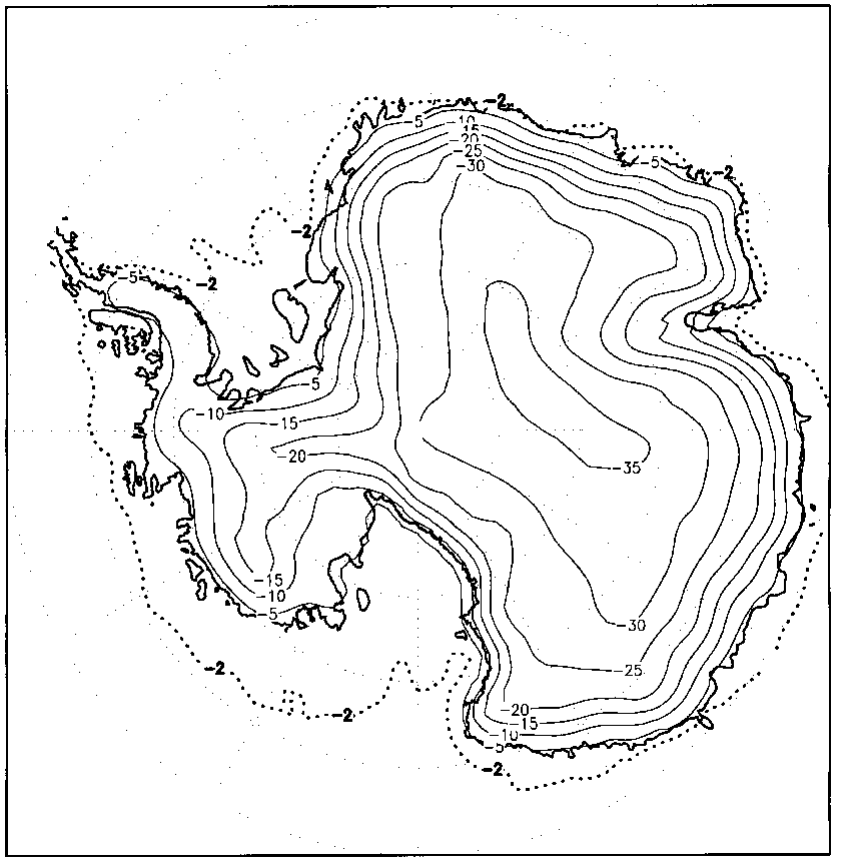

Fig. 8. Summer mean temperature under doubled $\mathrm{CO}_{2}$ concentration over Antarctica $\left({ }^{\circ} \mathrm{C}\right)$ as projected in the ECHAM4 T106 time-slice scenario. The dotted $-2^{\circ} \mathrm{C}$ isoline defines the lowest temperature at which ablation can occur.

imply that the thermal expansion of sea water might dominate the net contribution from the cryosphere to sea-level rise over the next decades. Yet, the negative contribution from the polar ice sheets to sea level may eventually reverse, if $\mathrm{CO}_{2}$ concentrations reach levels well above doubled values. This would then induce sufficient warming to initiate melt also on the Antarctic ice sheet, thereby significantly accelerating global sea-level rise. Thus, the deceleration of sea-level rise due to the net mass gain on the polar ice sheets may only be effective as long as $\mathrm{CO}_{2}$ concentrations can be stabilized below double the present values.

The largest uncertainties still inherent in these estimates are related to the contribution from the Greenland ice sheet, i.e. accumulation changes and uncertainties in the calculation of ablation which need further investigation, whereas over Antarctica, the response of the mass balance to $2 \times \mathrm{CO}_{2}$ forcing seems to be more robust and reliable.

\section{ACKNOWLEDGEMENTS}

The Swiss Center for Scientific Computing (CSCS) generously provided the necessary computer resources for the high-resolution climate-change experiments. We are grateful to the Max-Planck Institute for Meteorology (L. Bengtsson, E. Roeckner, U. Cubasch and U. Schlese) for the highly valued cooperation in the joint climate-modeling projects. This study is supported by the Swiss Bundesamt für Bildung und Wissenschaft (BBW) grant No. 95.0640 and the Alliance for Global Sustainability (AGS).

\section{REFERENGES}

Brinkop, S. and E. Roeckner. 1995. Sensitivity of a general circulation model to parameterisations of cloud-turbulence interactions in the atmospheric boundary layer. Tellus, 47A(2), 197-220.

Claussen, M., U. Lohmann, E. Roeckner and U. Schulzweida. 1994. A global 
data set of land-surface parameters. Hamburg, Max-Planck-Institut für Meteorologie. (Report 135.)

Cubasch, U. and 6 others. 1992. Time-dependent greenhouse warming computations with a coupled ocean-atmosphere model. Climate Dyn., 8(2), 55-69.

Cubasch, U., J. Waszkewitz, G. C. Hegerl and J. Perlwitz. 1995. Regional climate changes as simulated in time-slice experiments. Climatic Change, 31 (2-4), 273-304.

Genthon, C., J. Jouzel and M. Déqué. 1994. Accumulation at the surface of polar ice sheets: observation and modelling for global climate change. In Desbois, M. and F. Désalmand, eds. Global precipitation and climate change. Berlin, etc., Springer-Verlag, 53-76. (NATO ASI Series I: Global Environmental Change 26.)

Giorgetta, M. and M. Wild. 1995. The water vapor continuum and its representation in ECHAM4. Hamburg, Max-Planck-Institut für Meteorologie. (Report 162.)

Giovinetto, M. B., N. M. Waters and C. R. Bentley. 1990. Dependence of Antarctic surface mass balance on temperature, elevation, and distance to open ocean. 7. Geophys. Res., 95(D4), 3517-3531.

Gregory, J. M. and J. Oerlemans. 1998. Sea-level rise from glacier melt over the next century calculated from an AOGCM coupled to a glacier mass-balance model. Nature, 391 (6666), 474-476.

Leggett, J., W. J. Pepper and R. J. Swart. 1992. Emissions scenarios for the IPCC: an update. In Houghton, J. T., B. A. Callander and S. K. Varney, eds. Climate change 1992: the supplementary report to the IPCC scientific assessment. Cambridge, Cambridge University Press, 69-95.

Morcrette, J.-J. 1991. Radiation and cloud radiative properties in the ECMWF operational weather forecast model. f. Geophys. Res., 96(D5), 9121-9132.

Ohmura, A. and N. Reeh. 1991. New precipitation and accumulation maps for Greenland. 7. Glaciol., 37(125), 140-148.

Ohmura, A., M. Wild and L. Bengtsson. 1996a. A possible change in mass balance of Greenland and Antarctic ice sheets in the coming century. $\mathcal{F}$. Climate, 9(9), 2124-2135.

Ohmura, A., M. Wild and L. Bengtsson. 1996b. Present and future mass balance of the ice sheets simulated with GCM. Ann. Glaciol., 23, 187-193.

Ohmura, A., P. Calanca, M. Wild and M. Anklin. 1999. Precipitation, accumulation and mass balance of Greenland ice sheet. Z. Gletscherkd. Glazialgeol., 35(1), 1-20.

Roeckner, E. and 13 others. 1992. Simulations of the present-day climate with the ECHAM model: impact of model physics and resolution. Hamburg, MaxPlanck-Institut für Meteorologie. (Report 93.)

Roeckner, E. and 9 others. 1996. The atmospheric general circulation model ECHAM4: model description and simulation of present day climate. Hamburg, MaxPlanck-Institut für Meteorologie. (Report 218.)

Roeckner, E., L. Bengtsson, J. Feichter, J. Lelieveld and H. Rodhe. 1999. Transient climate change simulations with a coupled atmosphereocean GCM including the tropospheric sulfur cycle. F. Climate, 12(10), 3004-3032.

Thompson, S. L. and D. Pollard. 1997. Greenland and Antarctic mass balances for present and doubled atmospheric $\mathrm{CO}_{2}$ from the GENESIS version 2 global climate model. f. Climate, 10(5), 871-900.

Tiedtke, M. 1989. A comprehensive mass flux scheme for cumulus parameterization in large-scale models. Mon. Weather Rev., 117(8), 1779-1800.

Warrick, R. A., C. le Provost, M. F. Meier, J. Oerlemans and P. L. Woodworth. 1996. Changes in sea level. In Houghton, J. T., L. G. M. Filho, B. A. Callander, N. Harris, A. Kattenberg and K. Maskell, eds. Climate change 1995: the science of climate change. Cambridge, etc., Cambridge University Press, 359-405.

Wild, M., L. Dümenil and J.P. Schulz. 1996. Regional climate simulation with a high resolution GCM: surface hydrology. Climate Dyn., 12(11), 755-774.

Wild, M., A. Ohmura and U. Cubasch. 1997. GCM simulated surface energy fluxes in climate change experiments. f. Climate, 10(12), 3093-3110.

Wild, M., A. Ohmura, H. Gilgen, E. Roeckner, M. Giorgetta and J. J. Morcrette. 1998. The disposition of radiative energy in the global climate system: GCM-calculated versus observational estimates. Climate Dyn., 14(12), 853-869.

Williamson, D. L. and P. J. Rasch. 1989. Two dimensional semi-Lagrangian transport with shape-preserving interpolation. Mon. Weather Rev., 117(1), $102-129$. 